
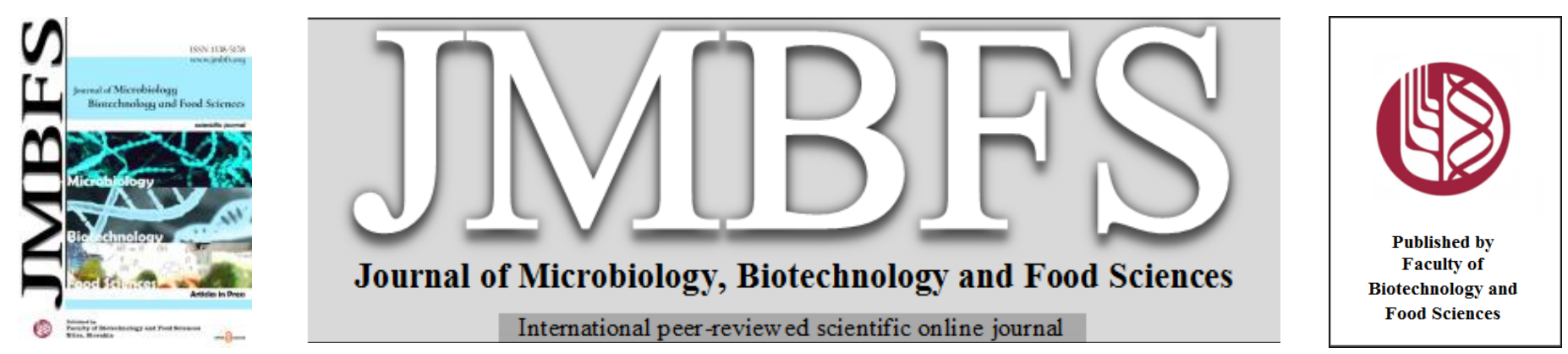

\title{
INVESTIGATION OF THE POTENTIAL UTILIZATIONS OF HUMAN MILK ORIGINATED Lactobacillus gasseri STRAINS IN AQUACULTURE AND SEAFOOD PRODUCTION
}

\author{
Ayse Gunyakti ${ }^{1,2}$, Meltem Asan-Ozusaglam ${ }^{1}$. \\ Address(es): Assoc.Prof.Dr. Meltem Asan-Ozusaglam \\ ${ }^{1}$ Department of Biotechnology, Faculty of Science and Letters, Aksaray University, 68100, Aksaray, Turkey. \\ ${ }^{2}$ Institute of Biotechnology, Ankara University, Ankara, 06110, Turkey.
}

*Corresponding author: meltemozusaglam@gmail.com

https://doi.org/10.15414/jmbfs.1626

\section{ARTICLE INFO}

Received 3. 5. 2019

Revised 12. 8. 2021

Accepted 13. 8. 2021

Published 1. 12. 2021

Regular article OPEN $\partial_{\text {ACCESS }}$

\begin{abstract}
In the current study, five Lactobacillus gasseri MA strains from human breast milk were investigated for their usage potentials in aquaculture and seafood products as probiotic and bio-protective. The strains were tested for their susceptibilities to various clinical antibiotics used in fish cultivation, antimicrobial activities against seven fish pathogens, alpha-amylase enzyme activities, and susceptibilities to sodium benzoate which used as a food preservative. The strains were susceptible to Ampicillin, Amoxicillin and Erythromycin antibiotics. Antimicrobial activity test results indicated that the inhibition zone diameters were ranged between $1.66 \mathrm{~mm}$ and $11.22 \mathrm{~mm}$ against various pathogens originated fish. The highest antimicrobial activity was recorded against the Aeromonas hydrophila ATCC $19570(11.22 \mathrm{~mm})$ for the MA-2 strain, while the lowest antimicrobial activity was determined against Vibrio anguillarum A4 $(1.66 \mathrm{~mm})$ for the MA-6 strain. L. gasseri MA-5, MA-3 and MA-6 showed alpha-amylase activity. The spectrophotometric and live-cell count data showed that all the strains exhibited resistance to sodium benzoate. The results suggest that $L$. gasseri MA strains could be good sources of probiotic for aquaculture and bio-protectives in seafood products.
\end{abstract}

\section{INTRODUCTION}

Recently, marine organisms are cultivated in very high populations, beyond the capacities of growing facilities (ponds, lakes etc.) to meet the increasing nutritional demands of growing human population and for more economic gain. However, this situation causes the cultured fish to be affected by many factors such as stress, water pollution, temperature, infectious diseases caused by microorganisms (Lakra and Ayyappan, 2003). These problems cause massive fish mortality and major economic losses. Antibiotics, various chemotherapeutics and vaccines are mainly used for coping with bacterial infections in aquaculture (Vaseeharan and Thaya, 2014). In particular, this widespread use of antibiotics leads to resistance in pathogenic strains, as well as the accumulation of antibiotic residues in fish. Ultimately, the consumption of these aquatic products caused the transmission of antibiotic residues to consumers. This can cause many health problems including antibiotic-resistant infections and, allergic reactions in humans (Cháfer-Pericás et al., 2010). For this reason, in aquaculture, the utilization of alternative natural preservatives such as plant fatty acids and extracts (Gunyakti et al., 2017), enzymes and probiotic cultures has recently gained attention. Among others, probiotic microorganisms are more environmentally friendly due to their non-toxic and non-pathogenic nature and are more preferred due to their contribution to growth and development by supporting the immune system of fish (Aly et al., 2008). Also, applying microbial enzymes in feed formulations not only improves digestion and feed utilization but also develops environmentally friendly and sustainable aquaculture (Ghosh and Mukhopadhyay, 2006).

According to the definition of Food and Agriculture Organization (FAO) and World Health Organization (WHO), probiotics are living microorganisms that have therapeutic effects on host health when taken in sufficient quantities (Grajek et al., 2005). Many Lactobacillus strains have been characterized as probiotics and the metabolites of these strains with antimicrobial properties are utilized as biocontrol agents for balancing aquatic habitats and the microbial flora of fish gastrointestinal tract (Ayoola et al., 2013). Fish microflora depends on the habitat, but the gastrointestinal microbiota of fish larvae can change very rapidly with the nutrition of beneficial microorganisms (Ng et al., 2000). For this reason, functional feeds that are enriched with probiotic microorganisms are very important (Dagá $\boldsymbol{e}$ al., 2013). Besides, lactic acid bacteria and various microbial enzymes such as phytase, amylase, lipase, glucanase and protease are also used as single or in combinations as the fish feed additives. Probiotic bacteria that produce enzymes such as amylase, lipase and protease help to regulate the digestive system of fish and produce various vitamins (De et al., 2014; Ghosh et al., 2007). Also, various lactic acid bacteria have been used as an alternative to artificial preservatives to obtain and store fermented fish products (Kopermsub and Yunchalard, 2010) However, some chemical additives are widely used to protect frozen seafood products from microbial spoilage. The most commonly used among these synthetic preservatives is sodium benzoate (SB, Food Additive European Code E211) (Hussain et al., 2011). SB is the salt of the benzoic acid and is used as a preservative $(0.1-0.2 \%)$ to inhibit the growth of some bacterial strains, mould and yeast in food industries.

On the other hand, Lactobacillus gasseri is a homofermentative and thermophilic probiotic bacteria and is one of the best known 50 Lactobacillus species (Kim and Rajagopal, 2001;Kawase et al., 2011). Previous studies have generally investigated the potential use of fish gut originated lactic acid bacteria in aquaculture. Up to now, several studies have reported the antimicrobial activities and bacteriocin production from L. gasseri strains of different origins (Gunyakti and Asan-Ozusaglam, 2018; Phukan et al., 2018; Quigley et al., 2019; Zhu et al., 2000). However, few published data focusing on the potential usage of these strains as probiotic agents in aquaculture.

For this reason, the current study was aimed to determine the potential usage of $L$ gasseri MA strains isolated from human milk (a safety source) as probiotic in fish culture and as bio preservatives in seafood products. The antimicrobial activity of the selected strains was investigated against seven fish pathogens such as Vibrio alginolyticus, Vibrio anguillarum M1, Vibrio anguillarum A4, Aeromonas hydrophila ATCC 19570, Lactococcus garvieae, Yersinia ruckeri, Streptococcus agalactiae Pas. Inst. 55118. Also, the antibiotic resistances, alpha-amylase enzyme activities and sodium benzoate (used in various fish and other canned products) resistances of five $L$. gasseri MA strains were measured. 


\section{MATERIAL AND METHODS}

\section{Bacterial strains and culture conditions}

Five $L$. gasseri MA strains from human milk were genetically identified by PCRbased molecular identification method (NCBI strain number:ATCC $33323=\mathrm{JCM}$ 1131). L. gasseri MA strains were cultured in MRS liquid/solid media and stored at $4{ }^{\circ} \mathrm{C}$ in glycerol stocks for further use.

\section{Determination of antibiotic sensitivity of MA strains}

Antibiotic resistance of the strains was determined by a previously reported method by Sharma et al. (2016). The resistance of L. gasseri MA strains to commercial antibiotics used in the treatment of fish diseases i.e., Erythromycin (E, $15 \mu \mathrm{g}$ ), Gentamycin (CN, $10 \mu \mathrm{g}$ ), Kanamycin (K, $30 \mu \mathrm{g}$ ), Ampicillin (AMP, $10 \mu \mathrm{g}$ ), Amoxicillin (AMC, $30 \mu \mathrm{g}$ ) was determined by disc diffusion method. Briefly, the cell densities of active $L$. gasseri MA strains were adjusted to Mc Farland 0.5 in a physiological saline solution (PSS: $0.865 \mathrm{~g} \mathrm{NaCl}$ ). L. gasseri strains were then inoculated on MRS agar medium $(100 \mu \mathrm{L})$ and spread with the sterile drigalsk spatula. Each antibiotic disc was placed on the MRS agar with three replicates and then left to incubate for $24 \mathrm{~h}$ at $37^{\circ} \mathrm{C}$. At the end of the incubation period, the inhibition zone diameters around the antibiotic discs were measured with Vernier calliper and the results were evaluated according to CLSI (Clinical and Laboratory Standards Institute) 2012 standards.

\section{Determination of antimicrobial activity}

The antimicrobial activity of the strains against various fish pathogens was determined according to the method described by Drago et al. (1997).

\section{Preparation of test microorganisms}

For the current study, seven fish pathogens (Vibrio alginolyticus, Vibrio anguillarum M1, Vibrio anguillarum A4, Aeromonas hydrophila ATCC 19570 Lactococcus garvieae, Yersinia ruckeri, Streptococcus agalactiae Pas. Inst. 55118) were used as test microorganisms. Test microorganisms were activated twice and adjusted to McFarland 0.5 standard.

\section{Preparation of L. gasseri MA supernatant}

For the determination of antimicrobial activity, L. gasseri MA strains were centrifuged at $5000 \mathrm{rpm}$ using a Universal $320 \mathrm{R}$ centrifuge for 15 minutes and the supernatants were sterilized with $0.2 \mu \mathrm{m}$ pore size microfilters. These sterilized supernatants were stored at $4{ }^{\circ} \mathrm{C}$.

\section{Agar well diffusion assay}

In well diffusion assay, $100 \mu \mathrm{L}$ of pathogen test microorganisms were inoculated onto the specific soft agar mediums and wells $(7 \mathrm{~mm})$ were made in triplicates. 100 $\mu \mathrm{L}$ of $L$. gasseri MA supernatants were loaded into the wells and then allowed to incubate for $24 \mathrm{~h}$ at appropriate temperatures for growth of each pathogenic microorganism. At the end of the incubation period, the inhibition zone values around the wells were measured with Vernier calliper and the results are given as averages of triplicates.

\section{Determination of alpha-amylase enzyme activity}

The alpha-amylase enzyme activity of the MA strains was determined using the method reported by Gupta et al. (2003) with some slight modifications. Alphaamylase enzyme activity was determined using supernatants of $L$. gasseri MA strains on nutrient agar medium containing $0.5 \%$ soluble starch $(\mathrm{w} / \mathrm{v})$ with spot culture method. For this purpose, the twice-activated cultures were centrifuged at $9000 \mathrm{rpm}$ for 15 minutes. The supernatants were dropped on a nutrient agar medium at 20 and $50 \mu \mathrm{L}$ in two different concentrations and allowed to incubate at $37{ }^{\circ} \mathrm{C}$ for $30 \mathrm{~min}$. At the end of the incubation period, the media was stained with iodine and clear zones were appeared around positive colonies.

\section{Sodium benzoate resistance}

The sodium benzoate resistance of $L$. gasseri MA strains was determined using the method reported by Gunyakti and Asan-Ozusaglam (2019). The MA strains cultures adjusted to Mc Farland 0.5 standard were inoculated as $1 \%$ to experimental and control groups with ten different concentrations $(0.015-1 \%)$ of sodium benzoate. The tubes were then allowed to incubate at $37^{\circ} \mathrm{C}$ for $24 \mathrm{~h}$. At the end of the incubation period, optical densities (OD) were measured spectrophotometrically at $600 \mathrm{~nm}$. Besides, acid production abilities of strains were determined on sodium benzoate containing (at ten different concentrations) media. MRS containing sodium benzoate at a concentration of $0.1 \%$ was used to determine live cell count. After dilution, the culture was inoculated on the MRS-agar medium in two replicates and then incubated at $37^{\circ} \mathrm{C}$ for $24 \mathrm{~h}$ under anaerobic conditions.

\section{Statistical analysis}

Statistical analysis was performed with the Mann-Whitney U-test to identify significant differences in antimicrobial activity and sodium benzoate resistance assay results. The differences were considered significant at a p-value of $<0.05$ The statistical analyses were conducted using SPSS version 22 (SPSS Inc, Chicago, IL, USA).

\section{RESULTS AND DISCUSSIONS}

\section{Determination of antibiotic sensitivity of MA strains}

As previously mentioned, resistance characteristics of MA strains to various commercial antibiotics were determined according to the disk diffusion method. Lactic acid bacteria with inhibition zone diameter as greater than $20 \mathrm{~mm}, 14-19$ $\mathrm{mm}$ and below $14 \mathrm{~mm}$ were considered as sensitive, moderately resistant and fully resistant, respectively according to CLSI 2012 standards (Table 1). All the $L$. gasseri MA strains were observed resistant to Gentamycin, Kanamycin and sensitive against Ampicillin, Amoxicillin, Erythromycin antibiotics. Among the strains, the highest sensitivity was observed for MA-3 strains against erythromycin antibiotics $(30.60 \mathrm{~mm})$. The highest resistance was observed for all the tested lactic acid bacteria against Kanamycin (no inhibition) and for MA-3 and MA-6 strains against Gentamicin (no inhibition) antibiotics.

Table 1 Antibiotic susceptibilities of L. gasseriMA strains

\begin{tabular}{lccccc}
\hline $\begin{array}{l}\text { L. gasseri } \\
\text { strains }\end{array}$ & $\begin{array}{c}\text { AM } \\
(\mathbf{1 0} \boldsymbol{\mu g})\end{array}$ & $\begin{array}{c}\text { AMC } \\
(\mathbf{3 0} \boldsymbol{\mu g})\end{array}$ & $\begin{array}{c}\text { CN } \\
(\mathbf{1 0} \boldsymbol{\mu g})\end{array}$ & $\begin{array}{c}\mathbf{E} \\
(\mathbf{1 5} \boldsymbol{\mu g})\end{array}$ & $\begin{array}{c}\text { K } \\
(\mathbf{3 0} \boldsymbol{\mu g})\end{array}$ \\
\hline MA-1 & $\mathrm{S}$ & $\mathrm{S}$ & $\mathrm{R}$ & $\mathrm{S}$ & $\mathrm{R}$ \\
\hline MA-2 & $\mathrm{S}$ & $\mathrm{S}$ & $\mathrm{R}$ & $\mathrm{S}$ & $\mathrm{R}$ \\
\hline MA-3 & $\mathrm{S}$ & $\mathrm{S}$ & $\mathrm{R}$ & $\mathrm{S}$ & $\mathrm{R}$ \\
\hline MA-5 & $\mathrm{S}$ & $\mathrm{S}$ & $\mathrm{R}$ & $\mathrm{S}$ & $\mathrm{R}$ \\
\hline MA-6 & $\mathrm{S}$ & $\mathrm{S}$ & $\mathrm{R}$ & $\mathrm{S}$ & $\mathrm{R}$ \\
\hline
\end{tabular}

${ }^{\mathrm{a}} \mathrm{CLSI}$, Clinical and Laboratory Standards Institute. The inhibition zones are evaluated according to the standard values given by CLSI. Susceptible $>20$, Intermediate \% 15-19, Resistant $<14$ (CLSI, 2012)

AM: Ampicillin, AMC: Amoxicillin, CN: Gentamicin, E: Erythromycin, K: Kanamycin, R: Resistant, S: Sensitive

In a previous study, the antibiotic resistance properties of two L. gasseri strains from human breast milk were observed as resistant to Gentamycin and Kanamycin while susceptible to Ampicillin and Erythromycin antibiotics (Martín et al. 2005). In another study, L. gasseri NLRI-312 strain isolated from feces of newborn infants was determined as resistant to Kanamycin while susceptible to Erythromycin antibiotics (Kim et al., 2006). Some sources have been reported trouble that lactic acid bacteria used as probiotic or starter cultures can transfer antibiotic resistance genes to other lactic acid bacteria or pathogenic microorganisms. The results of the present study are similar to the above reports which cleared that L. gasseri MA strains exhibit resistance profiles to some clinically tested antibiotics. However, it has been also reported that probiotic microorganisms contain antibiotic resistance genes in genomic structures, structural resistance (chromosomal resistance) do not constitute a safety concern on their own as long as these genes are not transferred by horizontal transfer (Darsanaki et al., 2013).

\section{Determination antimicrobial activity}

Lactic acid bacteria inhibit the development of many enteric pathogens and play an important role in the treatment of gastrointestinal disorders in humans and animals (Fernández et al., 2003). Therefore, the inhibition of pathogenic microorganisms is expected from a probiotic strain by secreting various antimicrobial substances. In this study, antimicrobial activities of L. gasseri MA strains against fish pathogens were determined by well diffusion method (Table 2) The inhibition zone diameters for MA strains against the seven fish pathogens varied from $1.66 \mathrm{~mm}$ to $11.22 \mathrm{~mm}$. The highest antimicrobial activity was determined for the MA-2 strain against A. hydrophila ATCC 19570 while the lowest activity was determined against the $V$. anguillarum A4 for MA-6 strain Among the tested strains, only MA-1 strain did not show any inhibitory activity against the only Y. ruckeri. There are average differences between the obtained data of antimicrobial activity among L. gasseri MA strains. However, the statistical analysis indicated that there are no significant difference between these results $(p>0.05)$. The probable cause is that all the bacteria tested are different strains but the same bacteria (L. gasseri). 
Table 2 Antimicrobial activities of L. gasseriMA strains

Inhibition zone diameter ( $\mathrm{mm})$

\begin{tabular}{|c|c|c|c|c|c|c|c|c|c|}
\hline \multirow[b]{3}{*}{ Test Microorganisms } & \multirow{2}{*}{\multicolumn{5}{|c|}{ L. gasseri strains (Mean \pm standard deviation) }} & \multirow{2}{*}{\multicolumn{4}{|c|}{ Antibiotics (Mean \pm standard deviation) }} \\
\hline & & & & & & & & & \\
\hline & MA-1 & MA-2 & MA-3 & MA-5 & MA-6 & $\begin{array}{c}\mathrm{AM} \\
(10 \mu \mathrm{g})\end{array}$ & $\begin{array}{c}\mathrm{CN} \\
(10 \mu \mathrm{g})\end{array}$ & $\begin{array}{c}E \\
(15 \mu g)\end{array}$ & $\begin{array}{c}K \\
(30 \mu \mathrm{g})\end{array}$ \\
\hline A. hydrophila ATCC 19570 & $5.47 \pm 0.50^{\mathrm{a}}$ & $11.22 \pm 1.11$ & $10.31 \pm 1.46$ & $7.32 \pm 0.93$ & $6.29 \pm 0.77$ & $17.89 \pm 1.34$ & $13.38 \pm 0.84$ & $26.94 \pm 2.31$ & $13.23 \pm 0.52$ \\
\hline V.alginolyticus & $5.91 \pm 0.99$ & $4.99 \pm 0.31$ & $5.51 \pm 0.43$ & $4.55 \pm 0.58$ & $7.03 \pm 0.42$ & $16.95 \pm 1.11$ & $18.27 \pm 1.47$ & $20.99 \pm 2.04$ & $8.74 \pm 0.65$ \\
\hline V.anguillarum M1 & $4.18 \pm 0.00$ & $3.51 \pm 0.25$ & $3.07 \pm 0.20$ & $2.67 \pm 0.49$ & $3.05 \pm 0.22$ & $15.9 \pm 1.17$ & $18.30 \pm 0.30$ & $17.97 \pm 0.31$ & $6.91 \pm 0.20$ \\
\hline V.anguillarum A4 & $3.02 \pm 0.47$ & $3.37 \pm 0.73$ & $2.39 \pm 0.42$ & $3.15 \pm 0.27$ & $1.66 \pm 0.21$ & $17.52 \pm 0.58$ & $9.33 \pm 0.01$ & $17.53 \pm 1.04$ & $8.72 \pm .28$ \\
\hline L. garvieae & $5.18 \pm 0.47$ & $3.50 \pm 0.28$ & $4.63 \pm 0.03$ & $3.42 \pm 0.44$ & $3.97 \pm 0.22$ & $16.40 \pm 0.12$ & $17.30 \pm 0.95$ & $31.08 \pm 1.01$ & $10.42 \pm 0.27$ \\
\hline Y. ruckeri & $-\mathrm{b}$ & $4.48 \pm 0.82$ & $3.92 \pm 0.09$ & $4.14 \pm 0.20$ & $4.90 \pm 0.43$ & $18.92 \pm 0.88$ & - & $11.37 \pm 0.83$ & $12.37 \pm 0.41$ \\
\hline S. agalactiae Pas. Inst. 55118 & $4.27 \pm 0.83$ & $4.73 \pm 0.51$ & $3.99 \pm 0.59$ & $6.93 \pm 0.72$ & $5.31 \pm 0.38$ & $35.34 \pm 3.40$ & - & $30.28 \pm 1.68$ & $16.25 \pm 1.18$ \\
\hline
\end{tabular}

AM: Ampicillin, CN: Gentamicin, E: Erythromycin, K: Kanamycin

${ }^{a}$ Diameter of the inhibition zone including disc diameter. Values are reported as means \pm SD of three separate experiments.

${ }^{\mathrm{b}}$ Indicates no antimicrobial activity.

Until now, there are quite a limited number of studies in the literature regarding the activity of L. gasseri strains against fish pathogens (Sahoo et al., 2015). In a previous study, Pirarat $\boldsymbol{e t}$ al. (2009) investigated the antimicrobial activity of human-induced Lactobacillus rhamnosus ATCC 53103 strain against some fish and frog pathogens by disc diffusion and agar spot methods. L. rhamnosus strain was found to have antimicrobial activity against all of the test pathogens $(A$. hydrophila, S. agalactiae, Streptococcus iniae, Chryseobacterium indologenes and Edwardsiella tarda). In another study, the antimicrobial activity of Bacillus subtilis UTM 126 against $V$. alginolyticus reported with $10-15 \mathrm{~mm}$ inhibition zone diameter (Balcázar et al., 2008;Balcázar and Rojas-Luna 2007). In this study, L. gasseri MA-2 strain showed inhibitory activity against $V$. alginolyticus with zone diameters of $7.03 \mathrm{~mm}$. Balcázar et al. (2008) tested the antimicrobia potential of different fish originated probiotics such as Lactococcus lactis CLFP 101, L. fermentum CLFP 24 and L. plantarum CLFP 238 strains against $V$. anguillarum, A. hydrophila, $Y$. ruckeri fish pathogens. The results of the study revealed that $L$. fermentum CLFP 24 and $L$. plantarum CLFP 238 strains exhibited no antimicrobial activity while L. lactis CLFP 101 strain showed activity against all the tested fish pathogens. In the current study, human breast milk originated $L$. gasseri MA strains showed inhibitory activity against all the tested fish pathogens except for MA-1 against the only Y. ruckeri pathogen. In another report by Zhou et al. (2010), the inhibitory effect of L. lactis RQ516 on A. hydrophila fish pathogen was recorded with $14.77 \mathrm{~mm}$ inhibition zone diameter. Considering this report, in our study, L. gasseri MA-2 strain showed a bit lower inhibitory activity (11.22 mm) against $A$. hydrophila pathogen than L. lactis strain RQ516.

Vibrio species, Aeromonas species and S. agalactiae are important pathogens, responsible for causing pathologic outbreaks and high rate mortalities in aquaculture (Wang et al., 2008; Evans et al., 2006). The consumption of $A$. hydrophila from contaminated water and food has been reported in a variety of studies which resulted in adverse effects on human health (Swift et al., 1997). Lactococcosis caused by L. garviae and yersiniosis caused by Y. ruckeri make a major economic loss in the fish breeding industry (Vendrell et al., 2006; Tobback et al., 2007). In the current study, antimicrobial activity was recorded for L. gasseri MA strains against vital pathogens such as Vibrio spp. (except MA-1), A hydrophila, Y. ruckeri, L. garviae, S. agalactiae Pas. Inst. 55118. For this reason, the use of $L$. gasseri MA strains in aquaculture may reduce or prevent epidemic diseases caused by pathogenic microorganisms. L. gasseri MA strains with antimicrobial activity may be recommended as a bio-preservative agent in aquaculture, seafood and canned fish products. The in-vitro results of the current study will also provide a basis for in-vivo studies.

\section{Determination of alpha-amylase enzyme activity}

The alpha-amylase is one of the most important industrial enzymes that cleave the alpha-1,4-glucosidic linkages of starch and produces different products such as glucose, maltose and maltotriose units (Gupta et al., 2003). Amylases and many other exogenous enzymes have been reported to be widely used as fish feed supplements. In the present study, alpha-amylase activity was observed for MA-5 (with $20 \mu \mathrm{L}$ of $L$. gasseri supernatant) and MA-3, MA-5, MA-6 (with $50 \mu \mathrm{L}$ of $L$. gasseri supernatant) (Figure 1). However, MA-1 and MA-2 strains showed no activity at both concentrations. Carter et al. (1992) observed that the alphaamylase enzyme used as dietary supplement affects positively the growth and development of fish. Amylases from bacteria promote starch digestion in the intestine of Cyprinus carpio (common carp) (Fusheng et al., 1994). The diets contain additional exogenous $\alpha$-amylase enzyme might raise the enzyme activity of the fish and improve feed digestibility (Ji et al., 2012). However, the purification of enzymes from the microbial sources could be expensive. Therefore, the usage of bacterial strains producing enzymes in feeding is a more economic way. Although most lactic acid bacteria do not have amylolytic enzymes, a limited number of lactic acid bacteria can produce alpha-amylase (Asoodeh et al., 2010). Ijeoma et al. (2015) reported amylase activity for Lactobacillus curvatus,
Lactobacillus plantarum, Lactococcus lactis subsp. lactis, Lactobacillus fermentum and Lactobacillus plantarum subsp. plantarum strains, while no activity for Weissella cibaria, Enterococcus faecalis, Enterococcus lactis, Leuconostoc pseudomesenteroides, Leuconostoc mesenteroides and Leuconostoc mesenteroides subsp. dextranicum strains. To our knowledge, the number of $L$. gasseri strains produce amylase enzyme is very limited (Oh $\boldsymbol{e t}$ al., 2015). This study will give a biotechnological perspective to the MA strains. Because of this property, the MA strains that produce amylase enzyme can be a new source for the feed industry and enzyme technology.

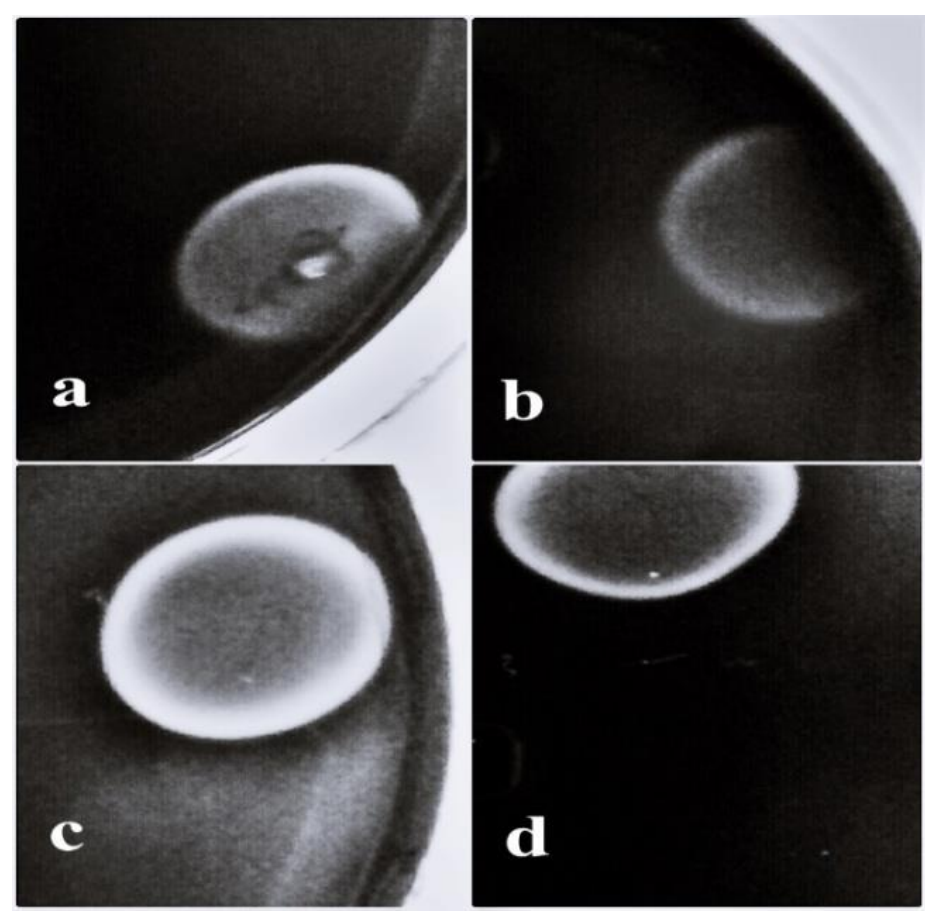

Figure 1 The alpha-amylase activity of L. gasseri MA strains

a: MA-3 $(50 \mu \mathrm{L}$ of supernatant $)$

b: MA-5 $(20 \mu \mathrm{L}$ of supernatant $)$

c: MA-5 $(50 \mu \mathrm{L}$ of supernatant $)$

d: MA-6 $(50 \mu \mathrm{L}$ of supernatant $)$

\section{Determination of sodium benzoate resistance}

Sodium benzoate is an artificial food additive used as a preservative in food and beverage industries against bacteria, fungi, and yeast (Chen et al., 2009). SB can be used in some seafood products or ice used in fish conservation (Zhang and Ma, 2013). Probiotic microorganisms naturally present in or added later to food products should be tolerant to SB. For this reason, this study can be crucial in determining the effects of SB during the applications of MA strains as a natural food additive. The development of MA strains in the sodium benzoate medium (OD) was generally reduced compared to the control group (except for $0.075 \%$ and $0.1 \mathrm{mg} / \mathrm{mL} \mathrm{SB}$ concentrations), but the strains never lost their viability (Table 3 ). There are mean differences between the observational data of spectrophotometric results of $L$. gasseri MA strains. The statistical analysis also indicated that there are significant differences between $L$. gasseri MA strains $(p \mid<0.05)$. Even, the average differences between MA 1 and MA-4, MA-1 and MA 5, MA 2 and MA-5 and MA-5 and MA- 6 at various SB concentrations are statistically different at the 
significance level of $0.05(p \mid<0.05)$. The tested MA strains originated from human milk are the same bacteria ( $L$. gasseri) but different strains. Therefore, the strains showed different resistance activities against various SB concentrations.

The $\mathrm{pH}$ values of the MA strains after culturing in media contained differen concentrations of SB (Table 4) showed decreases compared to the initial $\mathrm{pH}$ values This indicates that the strains survive throughout the incubation period and that initial $\mathrm{pH}$ values decreased with the production of various organic acids. However, MA-2 and MA-3 strains were found to have a value close to their initial $\mathrm{pH}$ values in a sodium benzoate medium with a concentration of $1 \mathrm{mg} / \mathrm{mL}$. As the application rate of sodium benzoate as a food preservative in various food industries is generally $0.1 \%$, live-cell counts of strains have been evaluated at this concentration. The number of viable cells of MA strains was found to be in the range of 10.78-6.85 Log CFU/mL (Table 5). The viable cell counts of four $L$. gasseri strains (MA-1, MA-2, MA-3, MA-6) showed bit decreases when compared to the control group. However, it was observed that MA-5 showedincreased growth and this result was following the spectrophotometric data. Up to now, no study has been reported on the resistance properties of $L$. gasseri strains to sodium benzoate. Considering the results obtained in this study, it was determined that all MA strains were resistant to $0.1 \% \mathrm{mg} / \mathrm{mL} \mathrm{SB}$, which is generally used concentration in food products.

\begin{tabular}{lccccc} 
Table 3 The resistance properties of L. gasseri MA strains against sodium benzoate (spectrophotometric) \\
\cline { 2 - 6 } $\begin{array}{l}\text { Sodium benzoate } \\
\text { concentrations (mg/mL) }\end{array}$ & MA-1 & MA-2 & MAsseri strains \\
\hline Control & $0.068 \pm 0.00$ & $1.54 \pm 0.00$ & $1.58 \pm 0.00$ & $1.88 \pm 0.00$ & $1.67 \pm 0.00$ \\
\hline $\mathbf{0 . 0 1 5}$ & $0.67 \pm 0.14$ & $1.22 \pm 0.06$ & $1.08 \pm 0.29$ & $1.59 \pm 0.12$ & $1.58 \pm 0.10$ \\
\hline $\mathbf{0 . 0 2 5}$ & $0.47 \pm 0.09$ & $0.46 \pm 0.03$ & $1.44 \pm 0.21$ & $1.76 \pm 0.03$ & $0.48 \pm 0.00$ \\
\hline $\mathbf{0 . 0 5 0}$ & $0.60 \pm 0.05$ & $1.51 \pm 0.01$ & $0.63 \pm 0.05$ & $0.59 \pm 0.05$ & $0.60 \pm 0.06$ \\
\hline $\mathbf{0 . 0 7 5}$ & $1.64 \pm 0.16$ & $1.46 \pm 0.01$ & $1.62 \pm 0.02$ & $1.74 \pm 0.01$ & $1.28 \pm 0.01$ \\
\hline $\mathbf{0 . 1}$ & $1.74 \pm 0.02$ & $1.36 \pm 0.00$ & $1.54 \pm 0.06$ & $1.89 \pm 0.02$ & $1.67 \pm 0.05$ \\
\hline $\mathbf{0 . 2}$ & $0.47 \pm 0.02$ & $0.53 \pm 0.05$ & $0.52 \pm 0.00$ & $1.28 \pm 0.06$ & $1.18 \pm 0.21$ \\
\hline $\mathbf{0 . 3}$ & $0.37 \pm 0.00$ & $0.38 \pm 0.03$ & $0.42 \pm 0.03$ & $0.41 \pm 0.03$ & $0.40 \pm 0.02$ \\
\hline $\mathbf{0 . 4}$ & $0.26 \pm 0.06$ & $0.84 \pm 0.07$ & $0.55 \pm 0.06$ & $0.56 \pm 0.05$ & $0.56 \pm 0.02$ \\
\hline $\mathbf{0 . 5}$ & $0.55 \pm 0.00$ & $0.38 \pm 0.02$ & $0.52 \pm 0.82$ & $0.54 \pm 0.85$ & $0.49 \pm 0.59$ \\
\hline $\mathbf{1}$ & $0.49 \pm 0.15$ & $0.21 \pm 0.06$ & $0.06 \pm 0.01$ & $0.61 \pm 0.02$ & $0.09 \pm 0.04$ \\
\hline
\end{tabular}

Sodium benzoate is used as preservatives in the food industry in a $\mathrm{pH}$ range below 4.5. The initial $\mathrm{pH}$ after the inoculation of the MA strains in the growth medium was nearly 5.6 (growth medium $\mathrm{pH}$ ). After incubation, the $\mathrm{pH}$ of the growth medium was generally decreased under $\mathrm{pH} 4.5$ which is below the $\mathrm{pH}$ limit at which sodium benzoate is active (Table 4)

Table 4 The $\mathrm{pH}$ value of $L$. gasseri MA strains after incubation in the medium containing sodium benzoate

\begin{tabular}{lcccccc}
\hline \multirow{2}{*}{ \% Sodium benzoate $(\mathbf{m g} / \mathbf{m L})$} & Initial $\mathbf{~ p H}$ & \multicolumn{5}{c}{ L. gasseri strains } \\
\cline { 3 - 7 } $\mathbf{0 . 0 1 5}$ & 5.619 & MA-1 & MA-2 & MA-3 & MA-5 & MA-6 \\
\hline $\mathbf{0 . 0 2 5}$ & 5.5 & 3.8 & 3.7 & 3.7 & 3.7 \\
\hline $\mathbf{0 . 0 5 0}$ & 5.628 & 3.9 & 3.9 & 3.9 & 3.9 & 3.8 \\
\hline $\mathbf{0 . 0 7 5}$ & 5.638 & 3.9 & 4.0 & 3.7 & 3.8 & 3.7 \\
\hline $\mathbf{0 . 1}$ & 5.639 & 3.9 & 3.9 & 3.8 & 3.8 & 3.9 \\
\hline $\mathbf{0 . 2}$ & 5.677 & 4.2 & 4.4 & 4.1 & 4.1 & 4.1 \\
\hline $\mathbf{0 . 3}$ & 5.605 & 4.1 & 4.1 & 3.9 & 3.9 & 3.9 \\
\hline $\mathbf{0 . 4}$ & 5.637 & 4.3 & 4.8 & 4.4 & 4.3 & 4.3 \\
\hline $\mathbf{0 . 5}$ & 5.640 & 4.4 & 5 & 4.7 & 4.3 & 4.4 \\
\hline $\mathbf{1}$ & 5.702 & 4.9 & 5.5 & 5.5 & 4.8 & 4.5 \\
\hline
\end{tabular}

The spectrophotometric data showed that the strains did not lose their viability after incubation (below $\mathrm{pH} 4.5$ ). Besides, the viable cell results slightly decreased as compared with the control group at the application concentration of sodium benzoate $(0.1 \%)$ in the food industry, suggesting that these strains survived under $\mathrm{pH} 4.5$ at which sodium benzoate was active (Table 5).

Table 5 Theviability of L. gasseriMA strains against sodium benzoate (Log $\mathrm{CFU} / \mathrm{mL})$

\begin{tabular}{lcc}
\hline L. gasseri strains & Control Group & $\begin{array}{c}\mathbf{0 . 1} \mathbf{~ m g / m L ~ S o d i u m ~} \\
\text { Benzoate }\end{array}$ \\
\hline MA-1 & 9.52 & 7.94 \\
\hline MA-2 & 9.33 & 6.85 \\
\hline MA-3 & 8.52 & 8.12 \\
\hline MA-5 & 8.93 & 10.26 \\
\hline MA-6 & 8.45 & 8.28 \\
\hline
\end{tabular}

As a result, when $\mathrm{SB}$ as a food preservative and MA strains as probiotic are used together in the food industry, these strains have a potential to be used as natura bio-preservatives against pathogen microorganisms as well as probiotic effects for the food industry (including marinated fish, fish sauces, salad dressings, etc.) since they do not lose their viability.

\section{CONCLUSION}

In this study, the usage potential of human milk origin L. gasseri MA strains in aquaculture and various seafood products was investigated. The results of this study demonstrate that $L$. gasseri MA strains can be good candidates for use as fish probiotics since these strains have a susceptibility to various clinical antibiotics in addition to their capacity to produce antimicrobial compounds against seven fish pathogens responsible for high morbidity and mortality in aquaculture. The results of this study also revealed that $L$. gasseri MA strains can be suggested as an alternative bio-preservative for chemical preservatives to limit the microbialinduced diseases in fish farming. It is also suggested that strains having positive alpha-amylase enzyme activity may be used as feed supplementation to enhance nutritional value in the fish feed industry and to increase fish feed utilization Additionally, all the strains were found resistant to sodium benzoate applied at different concentrations. Since strains are resistant to sodium benzoate, which is used as a preservative for canned fish or fish products, it may be advisable to use L. gasseri MA strains as alternative preservatives alone or in combination with sodium benzoate in such foods materials.

\section{REFERENCES}

Aly, S.M., Ahmed, Y.A.G., Ghareeb, A.A.A., \& Mohamed M.F. (2008). Studies on Bacillus subtilis and Lactobacillus acidophilus, as potential probiotics, on the immune response and resistance of Tilapia nilotica (Oreochromis niloticus) to challenge infections. Fish and Shellfish Immunology, 25, 128-136. https://doi.org/10.1016/j.fsi.2008.03.013

Asoodeh, A., Chamani, J., \& Lagzian, M. (2010). A novel thermostable, acidophilic $\alpha$-amylase from a new thermophilic "Bacillus sp. Ferdowsicous" isolated from Ferdows hot mineral spring in Iran: Purification and biochemical characterization. International Journal of Biological Macromolecules, 46, 289297. https://doi.org/10.1016/j.ijbiomac.2010.01.013

Ayoola, S., Ajani, E., \& Fashae, O. (2013). Effect of probiotics (Lactobacillus and Bifidobacterium) on growth performance and hematological profile of Clarias gariepinus juveniles. World Journal of Fish and Marine Sciences, 5, 1-8. Doi:10.5829/idosi.wjifms.2013.05.01.6582

Balcázar, J.L., \& Rojas-Luna, T. (2007). Inhibitory activity of probiotic Bacillus subtilis UTM 126 against Vibrio species confers protection against vibriosis in juvenile shrimp (Litopenaeus vannamei). Current Microbiology, 55, 409-412. https://doi.org/10.1007/s00284-007-9000-0

Balcázar, J.L., Vendrell, D., de Blas, I., Ruiz-Zarzuela, I., Muzquiz, J.L., \& Girones, O. (2008). Characterization of probiotic properties of lactic acid bacteria 
isolated from intestinal microbiota of fish. Aquaculture, 278, 188-191. https://doi.org/10.1016/j.aquaculture.2008.03.014

Carter, C., Houlihan, D., \& McCarthy, I. (1992). Feed utilization efficiencies of Atlantic salmon (Salmo salar L.) parr: effect of a single supplementary enzyme. Comparative Biochemistry and Physiology Part A: Physiology, 101, 369-374. https://doi.org/10.1016/0300-9629(92)90548-5

Cháfer-Pericás, C., Maquieira, A., \& Puchades, R. (2010). Fast screening methods to detect antibiotic residues in food samples. Trends in Analytical Chemistry, 29, 1038-1049. https://doi.org/10.1016/j.trac.2010.06.004

Chen, Q., Huang, N.N., Huang, J.T., Chen, S., Fan, J., Li, C., \& Xie, F.K. (2009). Sodium benzoate exposure downregulates the expression of tyrosine hydroxylase and dopamine transporter in dopaminergic neuronsin developing zebrafish. Birth Defects Research Part B Developmental and Reproductive Toxicology, 86, 85-91. https://doi.org/10.1002/bdrb.20187

Clinical and Laboratory Standards Institute (2012). Performance standards for antimicrobial susceptibility testing; twenty-second informational supplement.CLSI, 32, 44-49.

Dagá, P., Feijoo, G., Moreira, M., \& Costas, D. (2013). Villanueva A. and Lema J., Bioencapsulated probiotics increased survival, growth and improved gut flora of turbot (Psetta maxima) larvae. Aquaculture International, 21, 337-345. https://doi.org/10.1007/s10499-012-9556-y

Darsanaki, R., Aliabadi, M., \& Chakoosari, M. (2013). Antibiotic resistance of lactic acid bacteria. Scientific Journal of Microbiology, 2, 201-206. doi 10.14196/sjm.v2i11.1051

Drago, L., Gismondo, M.R., Lombardi, A., De Haën, C., \& Gozzini, L. (1997). Inhibition of in vitro growth of Enteropathogens by new Lactobacillus isolates of human intestinal origin. FEMS Microbiology Letters, 153, 455-463. https://doi.org/10.1111/j.1574-6968.1997.tb12610.x

Lakra W., \& Ayyappan S. (2003). Recent advances in biotechnology applications to aquaculture. Asian-Australasian Journal of Animal Sciences, 16, 455462.https://doi.org/10.5713/ajas.2003.455

De, B.C., Meena, D., Behera, B., Das, P., Mohapatra, P.D., \& Sharma, A. (2014) Probiotics in fish and shellfish culture: immunomodulatory and ecophysiological responses. Fish Physiology and Biochemistry, 40, 921-971. https://doi.org/10.1007/s10695-013-9897-0

Evans, J.J., Pasnik, D.J., Klesius, P.H., \& Al-Ablani, S. (2006). First report of Streptococcus agalactiae and Lactococcus garvieae from a wild bottlenose dolphin (Tursiops truncatus). Journal of Wildlife Diseases, 42, 561-569. https://doi.org/10.7589/0090-3558-42.3.561

Fernández, M.F., Boris, S., \& Barbes, C. (2003). Probiotic properties of human Lactobacilli strains to be used in the gastrointestinal tract. Journal of Applied Microbiology, 94, 449-455. https://doi.org/10.1046/j.1365-2672.2003.01850.x

Fusheng, T, Xiaoyan, Z, \& Xingzhong, Z. (1994). The influences of common carp intestinal bacteria and its amylases on the host digestion. Journal of Fisheries of China/Shuichan Xuebao Shanghai, 18, 177-182.

Ghosh, K., \& Mukhopadhyay, P.K. (2006). Application of enzymes in aqua feeds. Aqua Feeds Formulation Beyond, 3(4), 7-10.

Ghosh, S., Sinha, A., \& Sahu, C (2007). Effect of probiotic on reproductive performance in female livebearing ornamental fish. Aquaculture Research, 38 , 518-526. https://doi.org/10.1111/j.1365-2109.2007.01696.x

Grajek, W., Olejnik A., \& Sip, A. (2005). Probiotics, prebiotics and antioxidants as functional foods. Acta Biochimica Polonica, 52, 665-671.

Gunyakti, A., Asan-Ozusaglam, M., \& Mujtaba, M. (2017). Assessment of Biological and Antioxidant Capacities of Myrtus communis L. Leaf and Fruit Extracts from Mediterranean Region of Turkey. Journal of Microbiology and Biotechnology Research, 7, 16-24. https://doi.org/10.24896/jmbr.2017733

Gunyakti, A., \& Asan-Ozusaglam, M. (2018). Investigation of the potential use of Lactobacillus gasseri originated from human breast milk as food additive. $L W T$ Food Science and Technology, 93, 613-619. https://doi.org/10.1016/j.1wt.2018.04.020

Gunyakti, A., \& Asan-Ozusaglam, M. (2019). Lactobacillus gasseri from human milk with probiotic potential and some technological properties. LWT- Food Science and Technology, 109, 261-269. https://doi.org/10.1016/j.1wt.2019.04.043 Gupta, R., Gigras, P., Mohapatra, H., Goswami, V.K., \& Chauhan, B. (2003) Microbial $\alpha$-amylases: A biotechnological perspective. Process Biochemistry, 38 , 1599-1616. https://doi.org/10.1016/S0032-9592(03)00053-0

Hussain, I., Zeb, A., \& Ayub, M. (2011). Evaluation of apple and apricot blend juice preserved with sodium benzoate at refrigeration temperature. World Journal of Agricultural Sciences, 7, 136-142.

Ijeoma, I., Okerentugba, P., \& Oranusi, N. (2015). Biotechnological characterization of lactic acid bacteria isolated from Ogi-a cereal fermented food product. New York Science Journal, 8 (12), 21-26. http://www.sciencepub.net/newyork

Ji, H., Sun, H. T., \& Xiong, D.M. (2012). Studies on activity, distribution, and zymogram of protease, $\alpha$-amylase, and lipase in the paddlefish Polyodon spathula. Fish Physiology and Biochemistry, 38(3), 603-613. https://doi.org/10.1007/s10695-011-9541-9

Kawase, M., He, F., Kubota, A., Miyazawa, K., Yoda, K., \& Hiramatsu, M. (2011) Strain-specific detection by pulsed-field gel electrophoresis of Lactobacillus gasseri TMC0356 in human feces after oral administration of these organisms Microbiology and Immunology, 55, 589-594. https://doi.org/10.1111/j.13480421.2011.00350.x

Kim, H., Jeong, S., Ham, J., Chae, H., Lee, J., \& Ahn, C. (2006). Antioxidative and probiotic properties of Lactobacillus gasseri NLRI-312 isolated from Korean infant feces. Asian-Australasian Journal of Animal Sciences, 19, 1335-1341. https://doi.org/10.5713/ajas.2006.1335

Kim, J.W., \& Rajagopal, S. (2001). Antibacterial activities of Lactobacillus crispatus ATCC 33820 and Lactobacillus gasseri ATCC 33323. Journal of Microbiology (Korea), 39, 146-148.

Kopermsub, P., \& Yunchalard, S. (2010). Identification of lactic acid bacteria associated with the production of plaa-som, a traditional fermented fish product of Thailand. International Journal of Food Microbiology, 138, 200-204. https://doi.org/10.1016/j.ijfoodmicro.2010.01.024

Martín, R., Olivares, M., Marín, M.L., Fernández, L., Xaus, J., \& Rodríguez, J.M. (2005). Probiotic potential of 3 lactobacilli strains isolated from breast milk. Journal of Human Lactation, 21, 8-17. https://doi.org/10.1177/0890334404272393

Nandi, A., Banerjee, G., Dan, S.K., Ghosh, K., \& Ray, A.K. (2017). Probiotic efficiency of Bacillus sp. in Labeo rohita challenged by Aeromonas hydrophila: assessment of stress profile, haemato-biochemical parameters and immune responses. Aquaculture Research, 48, 4334-45. https://doi.org/10.1111/are.13255 Ng, W.K., Lu, K.S., Hashim, R., \& Ali, A. (2000). Effects of feeding rate on growth, feed utilizationand body composition of a tropical bagrid catfish Aquaculture. International, 8, 19-29. https://doi.org/10.1023/A:1009216831360 Oh, K.W., Kim, M.J., Kim, H.Y., Kim, B.Y., Baik, M.Y., Auh, J.H., \& Park, C.S (2005). Enzymatic characterization of a maltogenic amylase from Lactobacillus gasseri ATCC 33323 expressed in Escherichia coli. FEMS Microbiology Letters, 252, 175-181. https://doi.org/10.1016/i.femsle.2005.08.050

Phukan, N., Brooks, A. E., \& Simoes-Barbosa, A. (2018). A cell surface aggregation-promoting factor from Lactobacillus gasseri contributes to inhibition of Trichomonas vaginalis adhesion to human vaginal ectocervical cells. Infection and Immunity, 86(8), e00907-17. https://doi.org/10.1128/IAI.00907-17

Pirarat N., Pinpimai K., Chankow K., Malila K., Chansue N., Niyomtham W., \& Rodkhum C. (2009). In Vitro efficacy of human-derived probiotic, Lactobacillus rhamnosus against pathogenic bacteria in fish and frogs. The Thai Journal of Veterinary Medicine, 39 (4), 305-310.

Quigley, L., Coakley, M., Alemayehu, D., Rea, M. C., Casey, P. G., O'Sullivan, O., \& Ross, P. (2019). Lactobacillus gasseri APC 678 Reduces Shedding of the Pathogen Clostridium difficile in a Murine Model. Frontiers in Microbiology, 10, 273. https://doi.org/10.3389/fmicb.2019.00273

Sahoo, T. K., Jena, P. K., Nagar, N., Patel, A. K., \& Seshadri, S. (2015). In vitro evaluation of probiotic properties of lactic acid bacteria from the gut of Labeo rohita and Catla catla. Probiotics and Antimicrobial Proteins, 7(2), 126-136 https://doi.org/10.1007/s12602-015-9184-8

Sharma, P., Tomar, S.K., Sangwan, V., Goswami, P., \& Singh, R. (2016) Antibiotic resistance of Lactobacillus sp. isolated from commercial probiotic preparations. Journal of Food Safety, 36, 38-51. https://doi.org/10.1111/jfs.12211 Swift, S., Karlyshev, A.V., Fish, L., Durant, E.L., Winson, M.K., Chhabra, S.R., Williams, P., Macintyre, S., \& Stewart, G.S. (1997). Quorum sensing in Aeromonas hydrophila and Aeromonas salmonicida: Identification of the LuxRI homologs AhyRI and AsaRI and their cognate $\mathrm{N}$-acylhomoserine lactone signal molecules. Journal of Bacteriology, 179, 5271-5281. doi:10.1128/jb.179.17.52715281.1997

Tobback, E., Decostere, A., Hermans, K., Haesebrouck, F., \& Chiers, K. (2007). Yersinia ruckeri infections in salmonid fish. Journal of Fish Diseases, 30, $257-$ 268. https://doi.org/10.1111/j.1365-2761.2007.00816.x

Vaseeharan, B., \& Thaya, R. (2014). Medicinal plant derivatives as immunostimulants: an alternative to chemotherapeutics and antibiotics in aquaculture. Aquaculture International, 22, 10791091.https://doi.org/10.1007/s10499-013-9729-3

Vendrell, D., Balcázar, J.L., Ruiz,-Zarzuela I.., De Blas, I., Gironés, O., \& Múzquiz, J.L. (2006). Lactococcus garvieae in fish: a review. Comparative Immunology, Microbiology \& Infectious Diseases, 29, 177-198. https://doi.org/10.1016/j.cimid.2006.06.003

Wang, Q., Liu, Q., Cao, X., Yang, M., \& Zhang, Y. (2008). Characterization of two TonB systems in marine fish pathogen Vibrio alginolyticus: their roles in iron utilization and virulence. Archives of Microbiology, 190, 595603.https://doi.org/10.1007/s00203-008-0407-1

Zhang, G., \& Ma, Y. (2013). Spectroscopic studies on the interaction of sodium benzoate, a food preservative, with calf thymus DNA. Food Chemistry, 141(1), 4147. https://doi.org/10.1016/j.foodchem.2013.02.122

Zhou, X., Wang, Y., Yao, J., \& Li, W. (2010). Inhibition ability of probiotic, Lactococcus lactis, against $A$. hydrophila and study of its immunostimulatory effect in tilapia (Oreochromis niloticus). International Journal of Engineering Science, 2, 73-80.

Zhu, W. M., Liu, W., \& Wu, D. Q. (2000). Isolation and characterization of a new bacteriocin from Lactobacillus gasseri KT7. Journal of Applied Microbiology, 88(5), 877-886. https://doi.org/10.1046/j.1365-2672.2000.01027.x 